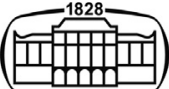

AKADÉMIAI KIADÓ

\title{
Structural characteristics of fixed-odds sports betting products
}

\section{Journal of Behavioral Addictions}

$10(2021) 3,371-380$

\section{Special Section on Sports and esports betting}

DOI:

$10.1556 / 2006.2021 .00008$ (c) 2021 The Author(s)

\section{REVIEW ARTICLE}

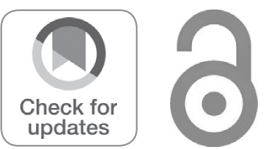

* Corresponding author E-mail: p.newall@cqu.edu.au

\author{
PHILIP W. S. NEWALL ${ }^{1 *}$ (อ), ALEX M. T. RUSSELL ${ }^{1}$ and \\ NERILEE HING ${ }^{2}$ \\ ${ }^{1}$ Experimental Gambling Research Laboratory, School of Health, Medical and Applied Sciences, \\ CQUniversity, Sydney, NSW, Australia \\ ${ }^{2}$ Experimental Gambling Research Laboratory, School of Health, Medical and Applied Sciences, \\ CQUniversity, Bundaberg, QLD, Australia
}

Received: November 22, 2020 • Revised manuscript received: January 12, 2021 • Accepted: February 6, 2021 Published online: April 8, 2021

\begin{abstract}
Background and aims: A literature exists on the structural characteristics of electronic gambling machines (EGMs), which are design innovations that can promote spending excessive time and money on these games. Fixed-odds sports betting products, where bettors place sports bets against a bookmaker, have also seen significant innovations in recent years. Despite some differences between these gambling products, similar structural characteristics could also be relevant to sports betting. The aim was to review previous research on contemporary fixed-odds sports betting products, and to identify whether structural characteristics from the EGM literature are also relevant to sports betting. Methods: Structural characteristics uncovered by two influential reviews of EGMs were identified, and their relevance to fixed-odds sports betting products discussed via a narrative review. Results: Structural characteristics of payout interval and potential betting frequency (in-play betting), multiplier potential (accumulators, complex bets, multis), win probability and payout ratio (all bets), bettor involvement (custom sports betting products, cash out), skill required (all bets), and near-misses (accumulators, complex bets, multis) were all identified in modern fixed-odds sports betting products. Discussion and conclusions: Fixed-odds sports betting products have increasingly incorporated structural characteristics previously found in EGMs. Future research could further assess the extent to which these structural characteristics contribute to fixed-odds sports bettors spending excessive amounts of time and money while betting. These findings can help guide further sports betting research, contribute to an improved understanding of the potential universality of gambling product design, and inform policy.
\end{abstract}

\section{KEYWORDS}

gambling, gambling products, product design, internet gambling, gambling innovation

\section{INTRODUCTION}

The "structural characteristics" of electronic gambling machines (EGMs) are design features that can promote spending excessive time and money on these games, which can therefore contribute to gambling-related harm (Browne et al., 2016; Wardle, Reith, Langham, \& Rogers, 2019), and which might make EGMs especially appealing to people with gambling problems (Cornish, 1978; Goodie, 2015; Griffiths, 1993; Landon et al., 2018; Livingstone, Woolley, Zazryn, Bakacs, \& Shami, 2008; Parke, J. \& Griffiths, 2006; Schüll, 2012). EGMs are one of the biggest drivers of gambling expenditure in many countries (The Economist, 2017), and have one of the strongest associations with problem gambling amongst established gambling forms (Delfabbro, King, Browne, \& Dowling, 2020). However, new gambling products are constantly being developed, for example via mobile devices (specifically smartphones) and online gambling, meaning that EGMs are not the only gambling product where product design is important for gamblers' welfare. For example, in the UK, legislative and taxation changes have contributed to the growth of the sports betting market since 2000 
(Forrest, 2008), and sports betting may now be the most popular gambling form with UK problem gamblers (PricewaterhouseCoopers, 2017). And while the UK Government has recently reduced the staking limit from $£ 100$ to $£ 2$ a spin on EGMs (Casey, 2018), there is no staking limit on sports bets. Sports betting is also growing in Australia (Queensland Government, 2019), and legal restrictions around sports betting have recently been relaxed in the US (Supreme Court of the United States, 2017). Previous research has analyzed the structural characteristics of sports betting inducements (Hing, Sproston, Brook, \& Brading, 2016), and individual characteristics of sports betting products (Lopez-Gonzalez, Estévez, \& Griffiths, 2017; Russell, Hing, Browne, Li, \& Vitartas, 2019), but a comprehensive overview of the structural characteristics of contemporary sports betting products is lacking.

Sports betting products can be split into fixed-odds products and betting exchange products (Franck, Verbeek, \& Nüesch, 2010). Fixed-odds products are the traditional way to bet on sports, and involve a bookmaker posting a set of odds on various outcomes for some upcoming event (Kuypers, 2000). This means that the size of the bettor's potential win is known at the time of betting. In comparison, in "parimutuel" betting, the odds depend on the amount of money placed on each outcome. Parimutuel betting is used for horseracing in some jurisdictions, but it not a common method of sports betting in most jurisdictions. All fixedodds bets are made against the bookmaker, who must come up with a set of odds that are sufficiently accurate to prevent skilled bettors from profiting excessively, and to ensure that the bookmaker has a reasonable spread of risk against various outcomes. A "balanced book" means that the bookmaker earns a constant profit no matter the outcome of the event (Stark \& Cortis, 2017), and this is a key riskmanagement tool for bookmakers (Levitt, 2004).

By comparison, betting exchanges allow sports bettors to bet against one another, with the exchange taking a small commission for each trade of bets. Betting exchanges allow sports bettors to take both roles in any potential sporting event, both as buyers of risk, and sellers of risk (like a bookmaker). This greater range of available options increases the complexity of betting exchange decisions (Axén \& Cortis, 2019, 2020), and may also make betting exchanges more prone to insider trading and market manipulation (Brown, 2012). The greater complexity and novelty of betting exchanges may explain why there is little research on betting exchanges. The current review therefore focuses only on fixed-odds sports betting products.

When gambling products are considered, EGMs and sports betting are at opposite ends of three relevant dimensions. EGMs involve what economists term "risk," as all probabilities can be known with precision and potentially communicated to gamblers. Sports betting contrastingly involves "uncertainty" (Knight, 1921), as any given event can only be experienced once, and the true probabilities cannot be known with certainty. EGMs traditionally do not involve skill, meaning that gamblers are almost guaranteed to lose money over time, although some recent EGMs have introduced skillbased components (Delfabbro, King, \& Gainsbury, 2020).
Sports betting is contrastingly perceived to be a highly-skilled gambling form (Buchdahl, 2003; Khazaal et al., 2012), which might allow people who are knowledgeable about the sport in question to find bets with positive long-run returns (Andersson, Edman, \& Ekman, 2005; Brown \& Reade, 2019; Butler, Butler, \& Eakins, 2020). Finally, women prefer EGMs over many other gambling forms, whereas sports betting is mostly engaged in by men (Hing, Russell, Tolchard, \& Nower, 2016; Merkouris et al., 2016).

Given these differences between EGMs and sports betting, it is interesting to see if they still share common structural characteristics. Accordingly, the aim of this review is to analyze research on contemporary fixed-odds sports betting products to identify if they have similar structural characteristics to EGMs. Common features shared by such different gambling products may inform a better understanding of the potential universality of gambling product design, as well as harm minimization measures (Newall, 2019; Schüll, 2012).

\section{METHOD}

Explicit references to structural characteristics are rare in the sports betting literature (Killick \& Griffiths, 2018; LopezGonzalez, Estévez, \& Griffiths, 2019; Lopez-Gonzalez \& Griffiths, 2017), providing little potential utility to database searches based on this term. This review will therefore include the structural characteristics of EGMs uncovered by influential reviews of this topic (Cornish, 1978), which were then later revisited by Griffiths (1993): payout interval and potential betting frequency, multiplier potential, win probability and payout ratio, bettor involvement, and skill required. The review will additionally consider near-misses as also reviewed by (Griffiths, 1993). These are themselves quite unique terms, which may also not be explicitly referenced in the sports betting literature. The review will therefore proceed in a narrative fashion, based on the authors' knowledge of these topics. The Discussion will further consider other potentially relevant structural characteristics of fixed-odds sports betting, albeit characteristics which have not yet been topics of systematic investigation in sports betting.

\section{RESULTS}

An overview of the results is provided in Table 1.

\section{Payout interval and potential betting frequency}

Payout interval refers to the time between when a bet is made and any winning bets are paid-out on. On traditional mechanical gambling machines, payout interval was determined by the maximum speed at which the physical reels could run. EGMs are not subject to these constraints, and can be programmed to have shorter payout intervals (Schüll, 2012). Shorter payout intervals increase the potential for harm, as increased gambling speed increases the potential 
Table 1. Overview of reviewed structural characteristics in EGMs and fixed-odds sports betting

\begin{tabular}{|c|c|c|c|}
\hline Structural Characteristic & Definition & EGMs & Sports betting (fixed-odds) \\
\hline $\begin{array}{l}\text { Payout interval/potential betting } \\
\text { frequency }\end{array}$ & $\begin{array}{l}\text { Time between when a bet is } \\
\text { made, and another bet can be } \\
\text { made, either due to the payout } \\
\text { of winnings or to the availability } \\
\text { of other potential bets }\end{array}$ & Very short & $\begin{array}{l}\text { Becoming shorter: in-play } \\
\text { betting and betting on in-game } \\
\text { contingencies, constant } \\
\text { availability of sport, and online } \\
\text { and smartphone mobile betting }\end{array}$ \\
\hline Multiplier potential & $\begin{array}{l}\text { Potential size of win from any } \\
\text { given size bet }\end{array}$ & $\begin{array}{l}\text { Enhanced via progressive } \\
\text { jackpots, free spin features }\end{array}$ & $\begin{array}{l}\text { High: through the range of long- } \\
\text { odds bets: Multis/accumulators/ } \\
\text { complex bets, inducements/ } \\
\text { promotions }\end{array}$ \\
\hline $\begin{array}{l}\text { Win probability and payout } \\
\text { ratio }\end{array}$ & $\begin{array}{c}\text { Payout ratio is the proportion of } \\
\text { all money bet that is paid out as } \\
\text { prizes, and not retained as the } \\
\text { house-edge }\end{array}$ & $\begin{array}{l}\text { Higher house-edge machines } \\
\text { result in higher losses }\end{array}$ & $\begin{array}{l}\text { Bets at longer odds have higher } \\
\text { house-edges }\end{array}$ \\
\hline Bettor involvement & $\begin{array}{c}\text { Degree of personal control over } \\
\text { outcomes }\end{array}$ & $\begin{array}{l}\text { Minimal (for non-skill-based } \\
\text { EGMs): players choose number } \\
\text { of lines and bet amount }\end{array}$ & $\begin{array}{l}\text { High: through researching form, } \\
\text { number of betting options, } \\
\text { custom sports betting products, } \\
\text { and ability to cash out bets }\end{array}$ \\
\hline Skill required & $\begin{array}{l}\text { Skill level involved in predicting } \\
\text { the outcome }\end{array}$ & $\begin{array}{l}\text { None (for non-skill-based } \\
\text { EGMs) }\end{array}$ & $\begin{array}{c}\text { Potentially high: forecasting } \\
\text { models based on past outcome } \\
\text { data, arbitrage. }\end{array}$ \\
\hline Near-misses & $\begin{array}{l}\text { A losing outcome that is very } \\
\text { close to a winning outcome }\end{array}$ & $\begin{array}{l}\text { Common: e.g. a payline with two } \\
\text { of three required symbols, and } \\
\text { the third required symbol being } \\
\text { on the next payline }\end{array}$ & $\begin{array}{c}\text { Can be common: accumulators, } \\
\text { complex bets, custom sports } \\
\text { betting products, same game } \\
\text { multis }\end{array}$ \\
\hline
\end{tabular}

maximum loss in any given interval of gambling (Livingstone et al., 2008; Schüll, 2012). Shorter payout intervals may also encourage impulsive betting and particularly appeal to people with gambling problems who tend to have higher trait impulsiveness (Amlung, Vedelago, Acker, Balodis, \& MacKillop, 2017). In EGMs, the payout interval is the main determinant of potential betting frequency. A more inclusive term for the related characteristic in sports betting may be number of betting opportunities. This is because only one bet can be made at a time on EGMs, while multiple sports bets can be made simultaneously. However, the effect of payout interval and number of betting opportunities on potential betting frequency is the same.

Changes within sport and innovations in sports betting products have both led to increases in potential betting frequency. First, the interval between different sporting events has decreased, in order to create a better product for TV (Goldblatt, 2007; Sharman, 2020). Soccer matches in the UK have a traditional kickoff time of $3 \mathrm{pm}$ Saturday, a time that is convenient for most fans to attend in the stadium. If all matches were played at this time, this would set a very slow betting frequency of up to an entire week for soccer bets. Such a schedule would also minimize the chance for soccer bettors to chase their losses (Zhang \& Clark, 2020), as any losing bets could only be potentially recovered in the following week's round of matches. However, match kick-off times are now staggered in time and across multiple days of the week, in order to maximize the number of games shown on TV, a change which also increases the exposure of sports fans to gambling marketing (Cassidy \& Ovenden, 2017; Purves, Critchlow, Morgan, Stead, \& Dobbie, 2020;
Roderique-Davies, Torrance, Bhairon, Cousins, \& John, 2020). This change in the structure of the sport can inadvertently help increase the potential betting frequency in soccer betting. Additionally, a greater number of foreign sports are now televised internationally, meaning that sports bets can be increasingly made at any time of day (Hing, Russell, Lamont, \& Vitartas, 2017).

Sports betting has also become more accessible through the advent of online gambling, including betting on mobile smartphones, allowing consumers to bet anywhere, anytime (Hing, Russell, Vitartas, \& Lamont, 2016; Lopez-Gonzalez et al., 2019). Prior to online betting, consumers would need to travel to a venue to place a bet, or have an account with a bookmaker to place a bet over the telephone. Online betting means that consumers can place bets closer to the start of an event, or outside of venue opening hours, thereby increasing the potential betting frequency. Further, consumers can have an account with the bookmaker, where winnings are returned directly to their account so that the consumer can quickly and easily place more bets if they so wish. This also increases the potential betting frequency compared to having to visit a venue to collect winnings. Convenience, 24/7 accessibility, speed of betting, and ease of financial transactions have been identified as facilitating harmful betting (Hing et al., 2015).

The second increase in potential betting frequency is due to an innovation in sports betting: in-play betting. For inplay betting, the odds are not restricted to only occurring before a given sporting event starts, and additionally update dynamically over the course of the event (Killick \& Griffiths, 2020; Parke, A. \& Parke, 2019). For example, if the home team scores the first goal in a soccer match, the bookmaker 
can respond by offering shorter odds on them to win for any in-play bets, and longer odds for the away team, which has not yet scored. A bettor who has placed a bet on the away team may react to this increased chances of loss by making further bets, now on the home team, to try to ensure a win, another example of how structural characteristics may influence loss chasing (Zhang \& Clark, 2020). Numerous studies have found that in-play sports betting has an especially strong association with problem gambling (Hing, Li, Vitartas, \& Russell, 2018; Hing, Russell, Li, \& Vitartas, 2018; LaPlante, Nelson, \& Gray, 2014; Lopez-Gonzalez et al., 2019; Russell, Hing, Li, \& Vitartas, 2019). While in-game bets can be placed on who will ultimately win the contest, they can also be placed on in-game events, such as who will score the next goal in soccer. Studies of UK soccer gambling advertising have found that advertisements for in-play betting on in-game events make up a large proportion of the bets that are advertised on TV (Newall, 2015, 2017; Newall, Thobhani, Walasek, \& Meyer, 2019).

However, some in-game bets can increase the potential betting frequency even more. Bets on the next point in tennis, or the next ball in cricket, have been called "microbets". They differ from in-play bets on in-game events, like the next goal scorer, in that the bet outcome has a definite near payout horizon, whereas the next goal may occur much later in the match. Microbets can therefore create payout intervals as short as a few seconds. This betting frequency is closer to that found on gambling machines than on traditional sports bets. In one study, $78 \%$ of sports bettors who made microbets met the threshold for problem gambling, compared to $29 \%$ of those who did not (Russell et al., 2019). Microbetting represents the culmination of sports betting's move towards becoming a continuous form of gambling.

\section{Multiplier potential}

Multiplier potential refers to the extent to which bets can be made on either one or a sequence of bets, with the odds becoming longer as more events are joined together in sequence (Cornish, 1978). In EGMs, multiplier potential might be most closely associated with progressive jackpots, which occasionally provide large bonuses for certain rare combinations, such as a royal flush in video poker ( $\mathrm{Li}$, Rockloff, Browne, \& Donaldson, 2016). However, other EGM features can provide free spins or bonus credits, which can similarly boost the potential winnings from any given wager (Livingstone et al., 2008). People classified as problem gamblers can be especially attracted by large potential wins (Kyonka \& Schutte, 2018; Ring et al., 2018), and often report big wins early in their gambling careers (Custer \& Milt, 1985; Turner, Zangeneh, \& Littman-Sharp, 2006), so the potential for a gambling form to create bets with long odds is a key structural characteristic.

Sports betting has always enabled the betting on a sequence of multiple events. An "accumulator" bet in soccer pays-out only on the final result if multiple soccer matches are successfully predicted. These winning probabilities are often small, and overestimated by casual observers (Nilsson \& Andersson, 2010). If enough events are bet on, then even small successful bets could win eye-watering amounts, and such events are often reported in the news, such as the parlaying of $£ 5$ into $£ 230,000$ (Love, 2019). Such accumulators, though, can have extremely long payout intervals, with some of the longest-odds accumulators being on various winners of season-long events.

Long-odds sports bets with shorter payout intervals can be created, however, by bets combining multiple aspects of a single sporting event. A bet can be placed on the first goalscorer and the final score of a soccer match, for example, to create a bet with multiplier potential and a relatively short payout interval. These bets have been called "complex" bets and "same game multis". These bets have been frequently observed in studies of UK gambling advertising on TV (Newall, 2015, 2017), with a gradual increase in odds and the number of constituent events over time (Newall et al., 2019). Some experimental evidence also suggests that some complex bets may appear attractive to sports bettors when shown via social media (Houghton \& Moss, 2020). Such bets can even conceivably be created as microbets, for example a bet on the number of yellow cards, corners and throw-ins to occur in the next $5 \mathrm{~min}$. This shows how sports bets with both short payout intervals and high multiplier potentials can be created in sports betting.

Sports bets with long odds can also be created via financial inducements (Newall et al., 2019), without necessarily relying on multiplier potential, such as bonus or improved odds offers (Hing et al., 2016), an offer which sports bettors find attractive (Hing, Russell, Thomas, \& Jenkinson, 2019). Experimental results suggest that bonus odds offers increase the attractiveness of long odds bets, specifically (Rockloff, Browne, Russell, Hing, \& Greer, 2019). These bonus bet offers often come with complicated terms and conditions on their redemption, however, which many sports bettors misunderstand (Hing et al., 2018). Bets with long odds may not therefore always be as attractive as they first seem.

\section{Win probability and payout ratio}

Following Griffiths (1993), we consider these two structural characteristics simultaneously, due to their close conceptual linkage. Win probability is the objective chance of winning any given bet, whereas the payout ratio refers to the total amount of money bet paid out as winnings. The payout ratio is the proportion of all money bet that is paid out as prizes, and which may be easier to conceptualize as the house-edge, the proportion of all money bet kept by the bookmaker as profit. There are two ways of describing this reality of commercial gambling (Parke, J., Parke, \& Blaszczynski, 2016), but some research suggests that the house-edge is easier to think about (Newall, Walasek, \& Ludvig, 2020), and so this term will be used going forward. The house-edge is a critical structural characteristic in gambling, as a house-edge is necessary for a sequence of bets over time to result in financial losses for the consumer, which then drive gambling-related harm (Markham, Young, \& Doran, 2016). 
Previous research indicates that gamblers can learn to avoid high house-edge EGMs in artificial laboratory conditions (Dixon, Fugelsang, MacLaren, \& Harrigan, 2013), but not in realistic casino scenarios (Lucas \& Spilde, 2019), therefore meaning that high house-edge EGMs produce the highest financial losses for gamblers.

Win probability is a function of both the odds and the house-edge. If the house-edge were constant across sports bets at different odds, then a comparison of odds would be sufficient to derive the relative win probability across different bets (Sauer, 1998). However, this is not the case: the house-edge tends to increase as the odds increase, as is true across different gambling forms (Turner, 2011). As first found in horse racing (Griffith, 1949; Snowberg \& Wolfers, 2010), and later confirmed in sports betting (Vaughan Williams, 1999), bets at long odds tend to have disproportionately high house-edges. That is, if the odds increase from 10 to 100 across two bets, then the true probability of winning at odds of 100 will be less than a tenth of the true probability of winning at odds of 10 .

This finding has been confirmed in sports betting, both with respect to a given type of bet, and when comparing different types of bets. So, for example in soccer, a bet on Team A to win at odds of 1.5 will tend to have a lower house-edge than a bet (of the same type) on Team B to win at odds of 5 (Buhagiar, Cortis, \& Newall, 2018; Constantinou \& Fenton, 2013). However, both of these bets may have lower house-edges than a bet with much higher odds of Team B to win by a scoreline of four goals to nil, a more complex bet type (Hassanniakalager \& Newall, 2019). Similar results also hold when comparing a bet on a single match with accumulator bets: adding more individual events to an accumulator bet will tend to increase the house-edge (Kuypers, 2000). Similar results are also expected when comparing same game multis to conventional bets in other sports. These results show how bets at long odds that offer high potential wins, which are the most attractive to problem gamblers (Kyonka \& Schutte, 2018; Ring et al., 2018), and are the least attractive from a rational betting perspective.

\section{Bettor involvement}

Bettor involvement refers to the potential actual or perceived control that gamblers have over their bets. There is perhaps a naturally higher level of bettor involvement in sports betting than in EGMs, as each sport bet must be selected afresh from the range of available options, whereas EGMs allow repeat bets to be made, which can lead to a state of betting while being "zoned-out" (Murch et al., 2020). Bettor involvement is a relevant structural characteristic given that problem gambling is frequently associated with the belief that a gambler's personal control can help them beat the odds (Goodie \& Fortune, 2013; Raylu \& Oei, 2004). There is an element of truth to this belief in sports betting, as described later. However, this belief is endorsed more than is truly warranted, making bettor involvement a relevant structural characteristic for sports betting. Perceived control has been promoted in sports betting advertising (Lopez-
Gonzalez, Estévez, \& Griffiths, 2018), but features most prominently as a structural characteristic of sports betting in a new range of "custom sports betting products" (LopezGonzalez, Jimenez-Murcia, \& Griffiths, 2019; Newall, Cassidy, Walasek, Ludvig, \& Meyer, 2020).

These new products give bettors an unprecedented degree of control over their bets. Fixed-odds bets have historically always been picked out of a finite list of odds. But custom sports betting products allow bettors to combine individual bets in a way that may be completely unique to that bettor. Broadly, "edit-bet" products allow bettors to combine individual events together on an operator's website, while "request-a-bet" products allow bettors to request odds via Twitter (Newall et al., 2020). Edit-bet products offer speed, as the custom bet's odds can be instantly quoted. Request-a-bet products offer variety, as a greater range of events can be conceivably combined in a custom bet request (the operator may refuse to quote odds on the requested bet). Engagement with custom sports betting products in general is correlated with problem gambling, gambling harm, and gambling consumption, suggesting these products are the most appealing to highly-engaged gamblers (Newall et al., 2020).

The public nature of Twitter data provides an opportunity to investigate features of the bets that people request odds on; by comparison, very little is known about the bets that are typically chosen in fixed-odds sports betting (Auer \& Griffiths, 2015). One study found that requested bets tended to involve combinations of multiple events with high potential wins, but which rarely paid-off, resulting in high house-edges in comparison to conventional sports bets (Newall, Walasek, Vázquez Kiesel, Ludvig, \& Meyer, 2019). Although that study did not manipulate the feature of bettor involvement, it did help to verify that the structural characteristics of multiplier potential and win probability and payout ratio are relevant to the sports bets that people actually inquire about.

"Cash-out" features are another structural characteristic that is relevant to bettor involvement. Cash-out first is perhaps most relevant to in-play betting, but also exists on betting exchanges (Brown \& Yang, 2017), and is also possible on long payout interval accumulator bets. If a team is winning at half time, and the bettor has a bet on them to win the match, the bettor can cash-out a proportion of the potential win in return for canceling the bet. This avoids the risk of the bet winning nothing if the team fails to win at full-time. Use of the cash-out feature is positively correlated with problem gambling (Lopez-Gonzalez et al., 2019). This may be because cash-out can further shorten payout intervals, as a bettor who has cashed-out at half-time may decide to make another bet for the second half. It may also be because cash-out provides an added element of personal agency into sports betting, which may appeal specifically to problem gamblers because of their frequent endorsement of illusion of control beliefs (Goodie \& Fortune, 2013; Raylu \& Oei, 2004).

However, the true cost of cashing-out is unknown to most bettors. This is because risk can be eliminated in another way: by putting on new "hedging" bets which 
eliminate the risk of the initial bet (Axén \& Cortis, 2020). Hedging is complicated and may take longer than cashingout, but can provide better sure returns. An analysis of bettors featured in newspaper stories as cashing-out their bets calculated individual losses of up to $£ 8,000$ compared to an optimal hedging strategy (Newall \& Cortis, 2019). This high implied hidden cost of hedging is one reason to suspect that cash-out is not merely correlated with problem gambling (Lopez-Gonzalez et al., 2019), but could worsen problem gamblers' financial situations, through its direct cost and ability to increase betting frequency.

\section{Skill required}

The skill level involved in successful sports betting has been estimated to be higher than the skill level involved in being a mutual fund manager (Getty, Li, Yano, Gao, \& Hosoi, 2018), a highly-paid profession which also involves the management of risk. Although there is undoubtably skill involved in sports betting, there are unlikely to be many long-run positive return prospects in the type of bets encouraged by various sports betting structural characteristics: those with high potential betting frequency, high multiplier potential, and low win probability and payout ratio. This section will briefly consider a few opportunities for positive long-run returns highlighted by previous sports betting research.

One approach is to build statistical models that can forecast probabilities more accurately than the bookmakers can. Operational research scientists often test forecasting approaches on sports betting data, due to the large available datasets of past odds and outcomes (Baboota \& Kaur, 2019; Brown, Rambaccussing, Reade, \& Rossi, 2018; Hassanniakalager, Sermpinis, Stasinakis, \& Verousis, 2020; Schumaker, Jarmoszko, \& Labedz Jr, 2016). This approach involves highly specialized skills, and published strategies may lose their profitability over time as markets adapt, which makes this a difficult approach to adopt.

"Arbitrage" involves exploiting price differentials for identical assets. If gold can be bought in London for $\$ 100$, and sold in New York for $\$ 150$, then a risk-free 50\% return on investment is possible. Arbitrage opportunities are also possible in sports betting, if a great enough odds differential can be found between different bookmakers (Cortis, 2015). With online sports betting, the odds offered by numerous bookmakers can be easily checked with dedicated sites such as oddschecker.com, which make it easier for bettors to shop around for the best odds. This may explain why there are more arbitrage opportunities in sports betting now than ever before (Constantinou \& Fenton, 2013). One technique that some sports bettors report using is called "matched betting," which purposively uses bookmakers' financial inducements to boost these risk-free returns, although we know of no research on this topic.

All skilled fixed-odds sports bettors face a similar risk, however, of having their accounts being closed for winning too much money (Buchdahl, 2016). One recent publication of a profitable sports betting strategy reports this occurrence, in fact (Kaunitz, Zhong, \& Kreiner, 2017). The strategy involves observing the distribution of bookmakers' odds for a given event, and only betting when at least one bookmaker offers unusually attractive odds. The authors reported profitable simulations with this strategy, but that these profits were hard to realize in practice as their betting accounts kept on being closed by operators.

\section{Near-misses}

Near-misses are a structural characteristic reviewed by Griffiths (1993) in relation to EGMs. If a machine shows apple-apple-pear, with an apple showing immediately above the pear, then a near-miss has occurred; a final apple in place of a pear would have produced a win. Near-misses can increase motivation to continue gambling (Clark, Lawrence, Astley-Jones, \& Gray, 2009), and are programmed to appear more often in EGMs than they would otherwise occur (Harrigan \& Dixon, 2009). Near-misses can naturally occur in sports, where for example one team might look to be winning but the other team stages a dramatic comeback. Some sports bets may also increase the "natural" rate of near-misses, again in close resemblance to EGMs (Harrigan \& Dixon, 2009).

Accumulator bets require all constituent events to occur, which will therefore naturally create a high proportion of near-misses to wins. Similar arguments apply to complex bets and same-game multis. If a bet has been placed on the first goalscorer and the final score of a soccer match, there can be many occurrences where one of these events happens or was close to happening and yet the bet did not pay-off. Similar arguments apply to the bets created via custom sports betting products, with one study showing that the average request involved an average of 4.8 individual conditions which all had to occur for the bet to pay-off (Newall et al., 2019). Cash-out features could additionally increase the rate of perceived near-misses in sports betting, as they can result in more situations where a losing bet could have hypothetically yielded a profit for the bettor. The potential for modern sports betting products to enhance gambling motivations via their frequency of near-misses is therefore an important area for future investigation.

\section{DISCUSSION}

EGMs and sports betting differ in terms of whether they involve risk or uncertainty, whether they involve skill, and whether they are more strongly associated with female or male gamblers. Despite these differences, structural characteristics which were first investigated with respect to EGMs (Cornish, 1978; Griffiths, 1993), were all found to be present in fixed-odds sports betting. These include payout interval and potential betting frequency, multiplier potential, win probability and payout ratio, bettor involvement, skill required, and near-misses. Further, some sports betting research has linked these structural characteristics with problem gambling (Hing et al., 2015; Lopez-Gonzalez et al., 2019; Newall et al., 2020). However, supporting evidence for 
these links remain partial, given the relatively limited research conducted on sports betting. Future research could further assess the extent to which these structural characteristics contribute to fixed-odds sports bettors spending excessive amounts of time and money while betting. By providing a framework that organized past fixed-odds sports betting research on structural characteristics, this review can inform future research, and potentially help contribute to a more universal theory of gambling product design (Newall, 2019; Schüll, 2012).

Future research could also consider additional structural characteristics of sports betting not included in previous EGM reviews. For example, "losses disguised as wins", are one recently discovered structural EGM characteristic, providing the potential for a gambler to bet $\$ 1$, “win" $\$ 0.50$ for an overall net return of $-\$ 0.50$, and yet be played stimulating congratulatory noises and feedback (Dixon, Harrigan, Sandhu, Collins, \& Fugelsang, 2010). It is possible that a similar characteristic could be relevant to some sports betting situations. Losses disguised as wins could conceivably occur when a sports bettor has cashed-out a bet to "win" less than the amount of their initial wager. Sports betting could also have unique structural characteristics without established analogs in EGMs, an issue that this review did not cover. This review also did not cover betting exchanges, a type of sports betting which may ultimately grow to eclipse fixed-odds sports betting.

\section{CONCLUSION}

The present review showed how there can be skill involved in producing positive long-run returns in some sports betting situations. Bettors are, however, more likely to be led by the structural characteristics of modern sports betting products into bets with long-run losses via potentially all of: high betting frequency, high multiplier potential, low win probability and payout ratio, high levels of bettor involvement, and frequent near-misses.

Funding sources: The authors received no funding for this research.

Authors' contribution: The authors contributed equally to this work.

Conflicts of interest: Philip Newall was a special advisor to the House of Lords Select Committee Enquiry on the Social and Economic Impact of the Gambling Industry. In the last three years Philip Newall has received research funding from Clean Up Gambling and the Think Forward Initiative, and has contributed to research projects funded by GambleAware, Gambling Research Australia, NSW Responsible Gambling Fund, and the Victorian Responsible Gambling Foundation. In 2019 Philip Newall received travel and accommodation funding from the Spanish Federation of Rehabilitated Gamblers, and in 2020 received an open access fee grant from Gambling Research Exchange Ontario. Alex Russell has received funding from Victorian Responsible Gambling Foundation; New South Wales Office of Responsible Gambling; Gambling Research Australia; New Zealand Ministry of Health; Australian Communications and Media Authority; National Association for Gambling Studies and the Alberta Gambling Research Institute. He has had travel expenses paid to present research by the Victorian Responsible Gambling Foundation and PsychMed. He is also affiliated with the University of Sydney. He declares no conflicts of interest in relation to this manuscript. Nerilee Hing has received research funds from the Victorian Responsible Gambling Foundation; New South Wales Office of Responsible Gambling; Queensland Justice and AttorneyGeneral; Gambling Research Australia; New Zealand Ministry of Health; Australian Communications and Media Authority; the Alberta Gambling Research Institute; Australian Government Department of Social Services; New Zealand Ministry of Health; and Australia's National Research Organisation for Women's Safety. She declares no conflicts of interest.

\section{REFERENCES}

Amlung, M., Vedelago, L., Acker, J., Balodis, I., \& MacKillop, J. (2017). Steep delay discounting and addictive behavior: A meta-analysis of continuous associations. Addiction, 112(1), 51-62.

Andersson, P., Edman, J., \& Ekman, M. (2005). Predicting the world cup 2002 in soccer: Performance and confidence of experts and non-experts. International Journal of Forecasting, 21(3), 565-576.

Auer, M., \& Griffiths, M. D. (2015). Theoretical loss and gambling intensity (revisited): A response to braverman et al. (2013). Journal of Gambling Studies, 31(3), 921-931.

Axén, G., \& Cortis, D. (2019). Extending the price constraints of betting markets. Journal of Behavioral and Experimental Finance, 23, 181-188.

Axén, G., \& Cortis, D. (2020). Hedging on betting markets. Risks, $8(88)$.

Baboota, R., \& Kaur, H. (2019). Predictive analysis and modelling football results using machine learning approach for English premier league. International Journal of Forecasting, 35(2), 741755 .

Brown, A. (2012). Evidence of in-play insider trading on a UK betting exchange. Applied Economics, 44(9), 1169-1175.

Browne, M., Langham, E., Rawat, V., Greer, N., Li, E., Rose, J., ... Best, T. (2016). Assessing gambling-related harm in victoria: $A$ public health perspective. Melbourne: Victorian Responsible Gambling Foundation.

Brown, A., Rambaccussing, D., Reade, J. J., \& Rossi, G. (2018). Forecasting with social media: Evidence from tweets on soccer matches. Economic Inquiry, 56(3), 1748-1763.

Brown, A., \& Reade, J. J. (2019). The wisdom of amateur crowds: Evidence from an online community of sports tipsters. European Journal of Operational Research, 272(3), 1073-1081. 
Brown, A., \& Yang, F. (2017). Salience and the disposition effect: Evidence from the introduction of "Cash-Outs" in betting markets. Southern Economic Journal, 83(4), 1052-1073.

Buchdahl, J. (2003). Fixed odds sports betting: Statistical forecasting and risk management. London, UK: High Stakes Publishing.

Buchdahl, J. (2016). Squares \& sharps, suckers \& sharks: The science, psychology \& philosophy of gambling, Oldcastle Books.

Buhagiar, R., Cortis, D., \& Newall, P. W. S. (2018). Why do some soccer bettors lose more money than others? Journal of Behavioral and Experimental Finance, 18(2018), 85-93. https:// doi.org/10.1016/j.jbef.2018.01.010.

Butler, D., Butler, R., \& Eakins, J. (2020). Expert performance and crowd wisdom: Evidence from English premier league predictions. European Journal of Operational Research, 288(1), 170-182. https://doi.org/10.1016/j.ejor.2020.05.034.

Casey, J. (2018). UK government confirms FOBT change now set for April 2019. Retrieved from https://www.gambling.com/ news/uk-government-confirms-fobt-change-now-set-for-april2019-1674400.

Cassidy, R., \& Ovenden, N. (2017). Frequency, duration and medium of advertisements for gambling and other risky products in commercial and public service broadcasts of English premier league football. Retrieved from https://osf.io/gprkv/? action $=$ download.

Clark, L., Lawrence, A. J., Astley-Jones, F., \& Gray, N. (2009). Gambling near-misses enhance motivation to gamble and recruit win-related brain circuitry. Neuron, 61(3), 481-490.

Constantinou, A. C., \& Fenton, N. E. (2013). Profiting from arbitrage and odds biases of the European football gambling market. The Journal of Gambling Business and Economics, 7(2), 4170.

Cornish, D. B. (1978). Gambling: A review of the literature and its implications for policy and research. London: Her Majesty's Stationery Office.

Cortis, D. (2015). Expected values and variances in bookmaker payouts: A theoretical approach towards setting limits on odds. The Journal of Prediction Markets, 9(1), 1-14.

Custer, R. L., \& Milt, H. (1985). When luck runs out: Help for compulsive gamblers and their families. New York: Facts on File.

Delfabbro, P., King, D. L., Browne, M., \& Dowling, N. A. (2020). Do EGMs have a stronger association with problem gambling than racing and casino table games? Evidence from a decade of australian prevalence studies. Journal of Gambling Studies, 36(2), 499-511. https://doi.org/10.1007/s10899-020-09950-5.

Delfabbro, P., King, D., \& Gainsbury, S. M. (2020). Understanding gambling and gaming skill and its implications for the convergence of gaming with electronic gaming machines. International Gambling Studies, 20(1), 171-183. https://doi.org/ 10.1080/14459795.2019.1662824.

Dixon, M. J., Fugelsang, J. A., MacLaren, V. V., \& Harrigan, K. A. (2013). Gamblers can discriminate 'tight'from 'loose'electronic gambling machines. International Gambling Studies, 13(1), 98111.

Dixon, M. J., Harrigan, K. A., Sandhu, R., Collins, K., \& Fugelsang, J. A. (2010). Losses disguised as wins in modern multi-line video slot machines. Addiction, 105(10), 1819-1824.

Forrest, D. (2008). Soccer betting in britain. In D. B. Hausch, \& W. T. Ziemba (Eds.), Handbook of sports and lottery markets (pp.
421-446) Elsevier. https://doi.org/10.1016/B978-044450744-0. 50023-8.

Franck, E., Verbeek, E., \& Nüesch, S. (2010). Prediction accuracy of different market structures-bookmakers versus a betting exchange. International Journal of Forecasting, 26(3), 448-459.

Getty, D., Li, H., Yano, M., Gao, C., \& Hosoi, A. (2018). Luck and the law: Quantifying chance in fantasy sports and other contests. SIAM Review, 60(4), 869-887.

Goldblatt, D. (2007). The ball is round: A global history of football. UK: Penguin.

Goodie, A. S. (2015). Associations between gambling games and gambling problems: Whole games compared with temporal, skill characteristics, and other structural characteristics. Current Addiction Reports, 2(3), 249-253.

Goodie, A. S., \& Fortune, E. E. (2013). Measuring cognitive distortions in pathological gambling: Review and meta-analyses. Psychology of Addictive Behaviors, 27(3), 730-743.

Griffith, R. M. (1949). Odds adjustments by american horse-race bettors. The American Journal of Psychology, 62(2), 290-294.

Griffiths, M. (1993). Fruit machine gambling: The importance of structural characteristics. Journal of Gambling Studies, 9(2), 101-120.

Harrigan, K. A., \& Dixon, M. (2009). PAR sheets, probabilities, and slot machine play: Implications for problem and non-problem gambling. Journal of Gambling Issues, (23), 81-110.

Hassanniakalager, A., \& Newall, P. W. S. (2019). A machine learning perspective on responsible gambling. Behavioural Public Policy, https://doi.org/10.1017/bpp.2019.9.

Hassanniakalager, A., Sermpinis, G., Stasinakis, C., \& Verousis, T. (2020). A conditional fuzzy inference approach in forecasting. European Journal of Operational Research, 283(1), 196-216.

Hing, N., Browne, M., Russell, A. M., Greer, N., Thomas, A., Jenkinson, R., et al. (2018). Where's the bonus in bonus bets? Assessing sports bettors' comprehension of their true cost. Journal of Gambling Studies, 35(2), 587-599.

Hing, N., Cherney, L., Gainsbury, S. M., Lubman, D. I., Wood, R. T., \& Blaszczynski, A. (2015). Maintaining and losing control during internet gambling: A qualitative study of gamblers' experiences. New Media \& Society, 17(7), 1075-1095.

Hing, N., Li, E., Vitartas, P., \& Russell, A. M. (2018). On the spur of the moment: Intrinsic predictors of impulse sports betting. Journal of Gambling Studies, 34(2), 413-428.

Hing, N., Russell, A. M. T., Lamont, M., \& Vitartas, P. (2017). Bet anywhere, anytime: An analysis of internet sports bettors' responses to gambling promotions during sports broadcasts by problem gambling severity. Journal of Gambling Studies, 33(4), 1051-1065.

Hing, N., Russell, A. M., Li, E., \& Vitartas, P. (2018). Does the uptake of wagering inducements predict impulse betting on sport? Journal of Behavioral Addictions, 7(1), 146-157.

Hing, N., Russell, A. M., Thomas, A., \& Jenkinson, R. (2019). Wagering advertisements and inducements: Exposure and perceived influence on betting behaviour. Journal of Gambling Studies, 35(3), 793-811. https://doi.org/10.1007/s10899-01809823-y.

Hing, N., Russell, A., Tolchard, B., \& Nower, L. (2016). Risk factors for gambling problems: An analysis by gender. Journal of Gambling Studies, 32(2), 511-534. 
Hing, N., Russell, A. M., Vitartas, P., \& Lamont, M. (2016). Demographic, behavioural and normative risk factors for gambling problems amongst sports bettors. Journal of Gambling Studies, 32(2), 625-641.

Hing, N., Sproston, K., Brook, K., \& Brading, R. (2016). The structural features of sports and race betting inducements: Issues for harm minimisation and consumer protection. Journal of Gambling Studies, 33(2), 685-704. https://doi.org/10.1007/ s10899-016-9642-6.

Houghton, S., \& Moss, M. (2020). Comparing football bettors' response to social media marketing differing in bet complexity and account type-An experimental study. Journal of Behavioral Addictions. https://doi.org/10.1556/2006.2020.00056.

Kaunitz, L., Zhong, S., \& Kreiner, J. (2017). Beating the bookies with their own numbers-and how the online sports betting market is rigged. arXiv Preprint arXiv:1710.02824.

Khazaal, Y., Chatton, A., Billieux, J., Bizzini, L., Monney, G., Fresard, E., et al. (2012). Effects of expertise on football betting. Substance Abuse Treatment, Prevention, and Policy, 7(18).

Killick, E. A., \& Griffiths, M. D. (2018). In-play sports betting: A scoping study. International Journal of Mental Health and Addiction, 17(6), 1456-1495. https://doi.org/10.1007/s11469018-9896-6.

Killick, E. A., \& Griffiths, M. D. (2020). Why do individuals engage in in-play sports betting? A qualitative interview study. Journal of Gambling Studies, 37(1), 221-240. https://doi.org/10.1007/ s10899-020-09968-9.

Knight, F. H. (1921). Risk uncertainty and profit. New York: Hart, Schaffner \& Marx.

Kuypers, T. (2000). Information and efficiency: An empirical study of a fixed odds betting market. Applied Economics, 32(11), 1353-1363.

Kyonka, E. G., \& Schutte, N. S. (2018). Probability discounting and gambling: A meta-analysis. Addiction, 113(12), 2173-2181.

Landon, J., du Preez, K. P., Page, A., Bellringer, M., Roberts, A., \& Abbott, M. (2018). Electronic gaming machine characteristics: It's the little things that count. International Journal of Mental Health and Addiction, 16(2), 251-265.

LaPlante, D. A., Nelson, S. E., \& Gray, H. M. (2014). Breadth and depth involvement: Understanding internet gambling involvement and its relationship to gambling problems. Psychology of Addictive Behaviors, 28(2), 396-403.

Levitt, S. D. (2004). Why are gambling markets organised so differently from financial markets? The Economic Journal, 114(495), 223-246.

Li, E., Rockloff, M. J., Browne, M., \& Donaldson, P. (2016). Jackpot structural features: Rollover effect and goal-gradient effect in EGM gambling. Journal of Gambling Studies, 32(2), 707-720.

Livingstone, C., Woolley, R., Zazryn, T. R., Bakacs, L., \& Shami, R. G. (2008). The relevance and role of gaming machine games and game features on the play of problem gamblers. Independent Gambling Authority.

Lopez-Gonzalez, H., Estévez, A., \& Griffiths, M. (2017). Marketing and advertising online sports betting: A problem gambling perspective. Journal of Sport and Social Issues, 41(3), 256-272.

Lopez-Gonzalez, H., Estévez, A., \& Griffiths, M. D. (2019). Internet-based structural characteristics of sports betting and problem gambling severity: Is there a relationship?
International Journal of Mental Health and Addiction, 17(6), 1360-1373. https://doi.org/10.1007/s11469-018-9876-x.

Lopez-Gonzalez, H., Estévez, A., \& Griffiths, M. D. (2018). Controlling the illusion of control: A grounded theory of sports betting advertising in the UK. International Gambling Studies, 18(1), 39-55.

Lopez-Gonzalez, H., \& Griffiths, M. D. (2017). "Cashing out” in sports betting: Implications for problem gambling and regulation. Gaming Law Review, 21(4), 323-326.

Lopez-Gonzalez, H., Jimenez-Murcia, S., \& Griffiths, M. D. (2019). Customization and personalization of sports betting products: Implications for responsible gambling. Gaming Law Review, 23(8), 572-577. https://doi.org/10.1089/glr2.2019. 2383.

Love, L. (2019). Lucky punter wins $£ 230,000$ after placing fiver on footy accumulator. Retrieved from https://www.dailyrecord.co. uk/news/scottish-news/lucky-punter-wins-230000-after20994927.

Lucas, A. F., \& Spilde, K. (2019). A deeper look into the relationship between house advantage and reel slot performance. Cornell Hospitality Quarterly, 60(3), 270-279.

Markham, F., Young, M., \& Doran, B. (2016). The relationship between player losses and gambling-related harm: Evidence from nationally representative cross-sectional surveys in four countries. Addiction, 111(2), 320-330.

Merkouris, S. S., Thomas, A. C., Shandley, K. A., Rodda, S. N., Oldenhof, E., \& Dowling, N. A. (2016). An update on gender differences in the characteristics associated with problem gambling: A systematic review. Current Addiction Reports, 3(3), 254-267.

Murch, W. S., Limbrick-Oldfield, E. H., Ferrari, M. A., MacDonald, K. I., Fooken, J., Cherkasova, M. V., et al. (2020). Zoned in or zoned out? Investigating immersion in slot machine gambling using mobile eye-tracking. Addiction, 115(6), 11271138.

Newall, P. W. S. (2015). How bookies make your money. Judgment and Decision Making, 10(3), 225-231.

Newall, P. W. S. (2017). Behavioral complexity of British gambling advertising. Addiction Research \& Theory, 25(6), 505-511. https://doi.org/10.1080/16066359.2017.1287901.

Newall, P. W. S. (2019). Dark nudges in gambling. Addiction Research \& Theory, 27(2), 65-67. https://doi.org/10.1080/ 16066359.2018.1474206.

Newall, P. W. S., Cassidy, R., Walasek, L., Ludvig, E. A., \& Meyer, C. (2020). Who uses custom sports betting products? Addiction Research \& Theory, https://doi.org/10.1080/16066359.2020. 1792887.

Newall, P. W. S., \& Cortis, D. (2019). High-stakes hedges are misunderstood too. A commentary on:"Valuing bets and hedges: Implications for the construct of risk preference". Judgment and Decision Making, 14(5), 605-607.

Newall, P. W. S., Moodie, C., Reith, G., Stead, M., Critchlow, N., Morgan, A., et al. (2019). Gambling marketing from 2014 to 2018: A literature review. Current Addiction Reports, 6(2), 4956. https://doi.org/10.1007/s40429-019-00239-1.

Newall, P. W. S., Thobhani, A., Walasek, L., \& Meyer, C. (2019). Live-odds gambling advertising and consumer protection. PloS One, https://doi.org/10.1371/journal.pone.0216876. 
Newall, P. W. S., Walasek, L., \& Ludvig, E. A. (2020). Equivalent gambling warning labels are perceived differently. Addiction, 111(9), 1762-1767. https://doi.org/10.1111/add.14954.

Newall, P. W. S., Walasek, L., Vázquez Kiesel, R., Ludvig, E. A. \& Meyer, C. (2019). Betting on intuitive longshots. Retrieved from psyarxiv.com/nk6tw.

Nilsson, H., \& Andersson, P. (2010). Making the seemingly impossible appear possible: Effects of conjunction fallacies in evaluations of bets on football games. Journal of Economic Psychology, 31(2), 172-180.

Parke, J., \& Griffiths, M. (2006). The psychology of the fruit machine: The role of structural characteristics (revisited). International Journal of Mental Health and Addiction, 4(2), 151-179.

Parke, A., \& Parke, J. (2019). Transformation of sports betting into a rapid and continuous gambling activity: A grounded theoretical investigation of problem sports betting in online settings. International Journal of Mental Health and Addiction, 17(6), 1340-1359.

Parke, J., Parke, A., \& Blaszczynski, A. (2016). Key issues in productbased harm minimisation: Examining theory, evidence and policy issues relevant in great britain. London: Responsible Gambling Trust.

PricewaterhouseCoopers. (2017). Remote gambling research: Interim report on phase II. Retrieved from https://about. gambleaware.org/media/1549/gamble-aware_remote-gamblingresearch_phase-2_pwc-report_august-2017-final.pdf.

Purves, R., Critchlow, N., Morgan, A., Stead, M., \& Dobbie, F. (2020). Examining the frequency and nature of gambling marketing in televised broadcasts of professional sporting events in the United Kingdom. Public Health, 184, 71-78.

Queensland Government. (2019). Australian gambling statistics. 1992-93 to 2017-18.(35th ed.) Retrieved from https://www. qgso.qld.gov.au/issues/2646/australian-gambling-statistics35th-edn-1992-93-2017-18.pdf.

Raylu, N., \& Oei, T. P. (2004). The gambling related cognitions scale (GRCS): Development, confirmatory factor validation and psychometric properties. Addiction, 99(6), 757-769.

Ring, P., Probst, C. C., Neyse, L., Wolff, S., Kaernbach, C., van Eimeren, T., et al. (2018). It's all about gains: Risk preferences in problem gambling. Journal of Experimental Psychology: General, 147(8), 1241-1255.

Rockloff, M. J., Browne, M., Russell, A. M., Hing, N., \& Greer, N. (2019). Sports betting incentives encourage gamblers to select the long odds: An experimental investigation using monetary rewards. Journal of Behavioral Addictions, 8(2), 268-276. https://doi.org/10.1556/2006.8.2019.30.
Roderique-Davies, G., Torrance, J., Bhairon, T., Cousins, A., \& John, B. (2020). Embedded gambling promotion in football: An explorative study of cue-exposure and urge to gamble. Journal of Gambling Studies, 36(3), 1013-1025. https://doi.org/10.1007/ s10899-020-09949-y.

Russell, A. M., Hing, N., Browne, M., Li, E., \& Vitartas, P. (2019). Who bets on micro events (microbets) in sports? Journal of Gambling Studies, 35(1), 205-223.

Russell, A. M., Hing, N., Li, E., \& Vitartas, P. (2019). Gambling risk groups are not all the same: Risk factors amongst sports bettors. Journal of Gambling Studies, 35(1), 225-246.

Sauer, R. D. (1998). The economics of wagering markets. Journal of Economic Literature, 36(4), 2021-2064.

Schüll, N. D. (2012). Addiction by design: Machine gambling in las vegas. Princeton, New Jersey: Princeton University Press.

Schumaker, R. P., Jarmoszko, A. T., \& Labedz Jr, C. S. (2016). Predicting wins and spread in the premier league using a sentiment analysis of twitter. Decision Support Systems, 88, 76-84.

Sharman, S. (2020). Gambling in football: How much is too much? Managing Sport and Leisure, https://doi.org/10.1080/23750472. 2020.1811135.

Snowberg, E., \& Wolfers, J. (2010). Explaining the Favorite-Long shot bias: Is it risk-love or misperceptions? Journal of Political Economy, 118(4), 723-746.

Stark, D., \& Cortis, D. (2017). Balancing the book: Is it necessary and sufficient? The Journal of Gambling Business and Economics, 11(1), 1-6.

Supreme Court of the United States. (2017). Murphy vs. national collegiate athletic association. Retrieved from https://www. supremecourt.gov/opinions/17pdf/16-476_dbfi.pdf.

The Economist. (2017). The world's biggest gamblers. Retrieved from https://www.economist.com/blogs/graphicdetail/2017/02/ daily-chart-4.

Turner, N. E. (2011). Volatility, house edge and prize structure of gambling games. Journal of Gambling Studies, 27(4), 607-623.

Turner, N. E., Zangeneh, M., \& Littman-Sharp, N. (2006). The experience of gambling and its role in problem gambling. International Gambling Studies, 6(2), 237-266.

Vaughan Williams, L. (1999). Information efficiency in betting markets: A survey. Bulletin of Economic Research, 51(1), 1-39.

Wardle, H., Reith, G., Langham, E., \& Rogers, R. D. (2019). Gambling and public health: We need policy action to prevent harm. BMJ, 365. https://doi.org/10.1136/bmj.11807.

Zhang, K., \& Clark, L. (2020). Loss-chasing in gambling behaviour: Neurocognitive and behavioural economic perspectives. Current Opinion in Behavioral Sciences, 31, 1-7. 